\title{
Bamboo, Orange, Ocean, and Beyond
}

The oldest Chinese poem is a very short one with eight words only, two in four pairs, roughly translated into English like this:

$\begin{array}{ll}\text { Cut a bamboo } & \text { 断竹 } \\ \text { Tie the ends } & \text { 续竹 } \\ \text { Shoot a mud } & \text { 飞土 } \\ \text { And chase that meat } & \text { 逐肉 }\end{array}$

In its straightforward description of the early hunting days when our ancestors were making bows from bamboo trees, we see how humans were destroying nature, as well as how smart they were in using bamboo branches to make a bow; we see how they captured animals and consumed their meat. From the earliest days of literature, nature poems were anti-nature; that is, about how opposed to nature human actions were. Later poets tried to sing of how beautiful nature was, but their words paled in the light of their cruelty in killing and eating other creatures.

The difference between nature poetry and eco-poetry seems to be the awareness, in the latter, of human nature: how we destroy the balance of the natural world around us. Part of the awareness results in an attempt to reinterpret the earlier poems. Why were there human voices in the deep, quiet forest in Wang Wei's "Deer Enclosure"? Why was sunset reflected on the green moss? Was it a beautiful scene for Wang Wei or horrible deforestation? The awakening sense of ecology is also seen in reevaluating our daily life, as Duo Duo writes in his poem "Gratitude": "In returning what we've taken, we take again." Duo Duo criticizes everything we do today to despoil nature, from mining to drilling to cutting down trees. Yet we imagine ourselves to be "singers of the earth"in singing, we forget for a brief moment our sinful actions. Singers or sinners, we are part of what we simultaneously enjoy and destroy. But we also see how small we are: a chrysanthemum, an oriole, a croaker. We are mixed into nature, as Song Wei suggests in his poem "Small Notes in My Old Age":

I return to the village and see lots of red peppers sunbathing on the threshing floor with me 
Xi Du expresses something similar in his poem "Seabirds" but with a broader perspective-the land and sea and living creatures and even things we build all responding to each other:

Sometimes the sea meanders to the land, folded as a seagull.

Sometimes the land walks to the sea, hiding in a boat.

The sea and land go deeper to each other through rain and lightning.

while crowds of white-robed monks rush to the sunrise

It is probably in this holistic view of the world that we feel less guilty of being a destructive and consumerist human, seeing ourselves as plants, birds, rain, and even "fifty-year-old dust" with feathers and wings, as Zhang Qinghua says in his poem "Dozing at Middle Age." That's how contemporary Chinese poets see themselves - instead of anthropomorphizing other species.

Another interesting feature of eco-poetry is the awareness of geography. Ancient poets name localities in their poems; later poets talk only vaguely about villages and rivers. In returning to the ancient tradition, contemporary Chinese poets are writing about their hometowns, or where they live and work. For instance, Song Wei writes about his hometown, Muchun, in Sichuan province; $\mathrm{Gu}$ Ma writes about a small town on the ancient Silk Road in northwest China; Li Suo writes about Kashgar, where she grew up; Jike Bu about Cold Mountains, where she has spent all her life; Lü De'an about a small village by the Ocean Corner where he lived; Jiang Hao about Hainan, the South Sea Island; Duo Duo, even more specifically, about the White Sand Gate in the South Sea Island, where he migrated to; Li Heng, who moves around, writes about "almost-notown." There is an old saying in Chinese, "every mountain raises one kind of person, and so does every river." For example, in Yu Xiaozhong's poem we feel the River Qi disposition, and in Zhang Er's the Buji River temperament.

In China, poets are not just poets but mountain poets, river poets, urban poets, or poets of the grassland. And they are not just any mountain poets or any river poets, but poets of specific mountains and rivers with names. Huang Bin is known for writing of his Shennongjia Mountains, and Yang Ke for his Flower Mountain in southern China. It is in this sense that locating them, as we do in the back of this collection, becomes meaningful: if you know a little bit of the geography of China (and the U.S. as well) or if you look up places on a map, you understand the poets better.

Ancient Chinese poets were poets of geography and traveled no less than we do today. Anyone reading Li Bai (701-762) cannot escape noticing the Yangtze River, literally the "Long River" in Chinese. The best known of his poems about the river is "Seeing Off Meng Haoran for Guangling at Yellow Crane Tower." In it, he describes traveling on the Yangtze to the Kingdom of $\mathrm{Chu}$, and meeting a local poet, who later departs eastward along the river to Yangzhou (Guangling): 
My old friend bids farewell to Yellow Crane Tower, traveling east to Yangzhou in the flowery March. His lonely sail, a distant shadow. Blue sky fades, only the Long River flows, flows to the far horizon.

Li Bai mentions over sixty rivers and eighty mountains in his poems. Du Fu (712-770), we see in his poetry, traveled even more. In fact, almost all the ancient Chinese poets and writers were travelers or migrants. The very first book in China's history, The Book of Mountains and Seas (山海经), is a series of volumes containing geographies as well as mythologies and polytheistic religions, with detailed descriptions of places inside China and beyond, including places in the Americas.

Hopefully, readers will remember some poets in this anthology by noticing the locality they write about-a river, a mountain, or a detail about where they live or have lived. But of course this collection cannot be a complete mapping of poets who write eco-poetry, but only the writing available at the time of publication. Mapping, mapping, mapping. Without drawing a map, Columbus couldn't have reached America. Without describing the mountains and seas in The Book of Mountains and Seas, migrating Asians couldn't have arrived in America and become the Indigenous people. Gary Snyder's "Turtle Island" says as much. The earliest Chinese words were carved into the bones of sea turtles, and these bones were used as oracles. Like the land that drifts slowly in the oceans for eons, turtles have long lives. Eco-poetry is a new perception of where we live, what's underneath us, what's around, and what's above. Hai Zi wrote "Asia Bronze" in 1984 to rebel against Misty poetry, which was much influenced by Western literature. The poem brought huge attention to Hai $\mathrm{Zi}$ and awakened an affirmation of the land beneath us, the bronze-colored soil of Asia. And our darker skin. The poem was perhaps the first eco-poem in contemporary China. However, eco-poetry is not limited by local borders, but presents a cosmic perspective, extending from where we are standing to wherever our imaginations take us. Beyond ocean and sky, even to the moon, which Hai Zi tells us Qu Yuan and other poets reached. Jiang Hao, in his poem "The Shape of the Ocean," writes:

When you ask me what the ocean's shape is like

I should bring you two sacks full of sea water.

They are the ocean's shape, like two eyes,

or what the ocean seems like because of a pair of eyes.

I always think of this poem's title and wonder if the oceans separate the land into continents, or if the land separates water into oceans. From South China and Taiwan to Southwest China, traveling along the Yangtze River, then west and north before winding down to the East Sea, and from there crossing the Pacific (flying over many islands), traveling eastward to California, and with 
many turns to America's East Coast, then crossing the Atlantic to Europe and back to Asia-words migrate like birds.

Migration is a normal pattern of contemporary life, as it was in ancient times. What's fascinating about eco-poetry is what it reveals about archaeology and anthropology, in addition to geography. The human-shaped scripts in Yang Ke's poem "Walking towards Flower Mountain" are the earliest writings of the Zhuang people in Guangxi, southern China.

From the tip of a boar's tusk I came

From a pheasant's fluffed-up feathers I came

From strange power of bone ornaments I came

Ethnic minority culture is an important component of this gathering of eco-poetry, as seen, for example, in the work of Aku Wuwu, Jidi Majia, and Jike $\mathrm{Bu}$, a member of the younger generation of Yi poets. In her poem, she sings about Suoma, a woman in the Cold Mountains region:

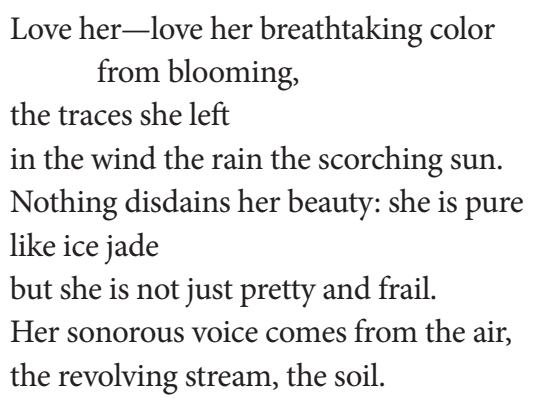

With the rise of eco-poetry, ethnic poets in China have begun to promote their cultures and languages, including their own writing systems. This is one difference between them and the Han majority poets, who write in Chinese and are concerned with reinventing a poetic form. For example, what strikes me in the first reading of Li Sen's "Orange in the Wilderness" is its three or four characters in each line, resembling the style used in the Book of Songs, the first collection of poems from the eleventh to sixth centuries BCE in China.

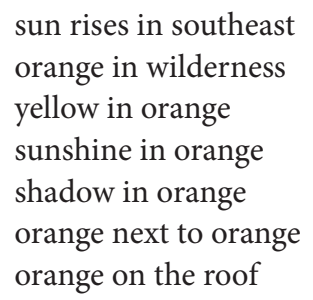

Another example of a search for fresh forms is "The Thirty-three tributaries of the Lancang River in Nanping County, Yunnan province" by Lei Pingyang 
(not included here). The poem was hugely controversial when it was first published in 2002, as it did little more than name each tributary and its length. Is it a poem or not? It doesn't have adjectives or verbs, but just names and numbers and the directions the rivers flow. But with its similar spirit to the style of The Book of Mountains and Seas, it is the rediscovery of an ancient way of writing. It's as informative as school textbooks, which reminds me of Marianne Moore's "Poetry" (1924): "nor is it valid/to discriminate against 'business documents and/school-books." It is also the very nature of detailed descriptions of things in Moore's poetry that makes her a pioneer eco-poet. She writes in "Sea Unicorns and Land Unicorns":

With their respective lions-

"mighty monoceroses with immeasured tayles"-

the long keel of white exhibited in tumbling,

disperses giant weeds

and those sea snakes whose forms, looped in the foam, "disquiet shippers."

What surprises me most is the "monoceros" at the beginning of this poem, which I interpret as the Monoceros (Latin: "unicorn") constellation that parallels with the unicorns. This is why I see in some American poets the holistic perspectives of ancient Chinese, who look at the land, the sea, and the constellations above in forming their mythologies of what's around us and beyond. 


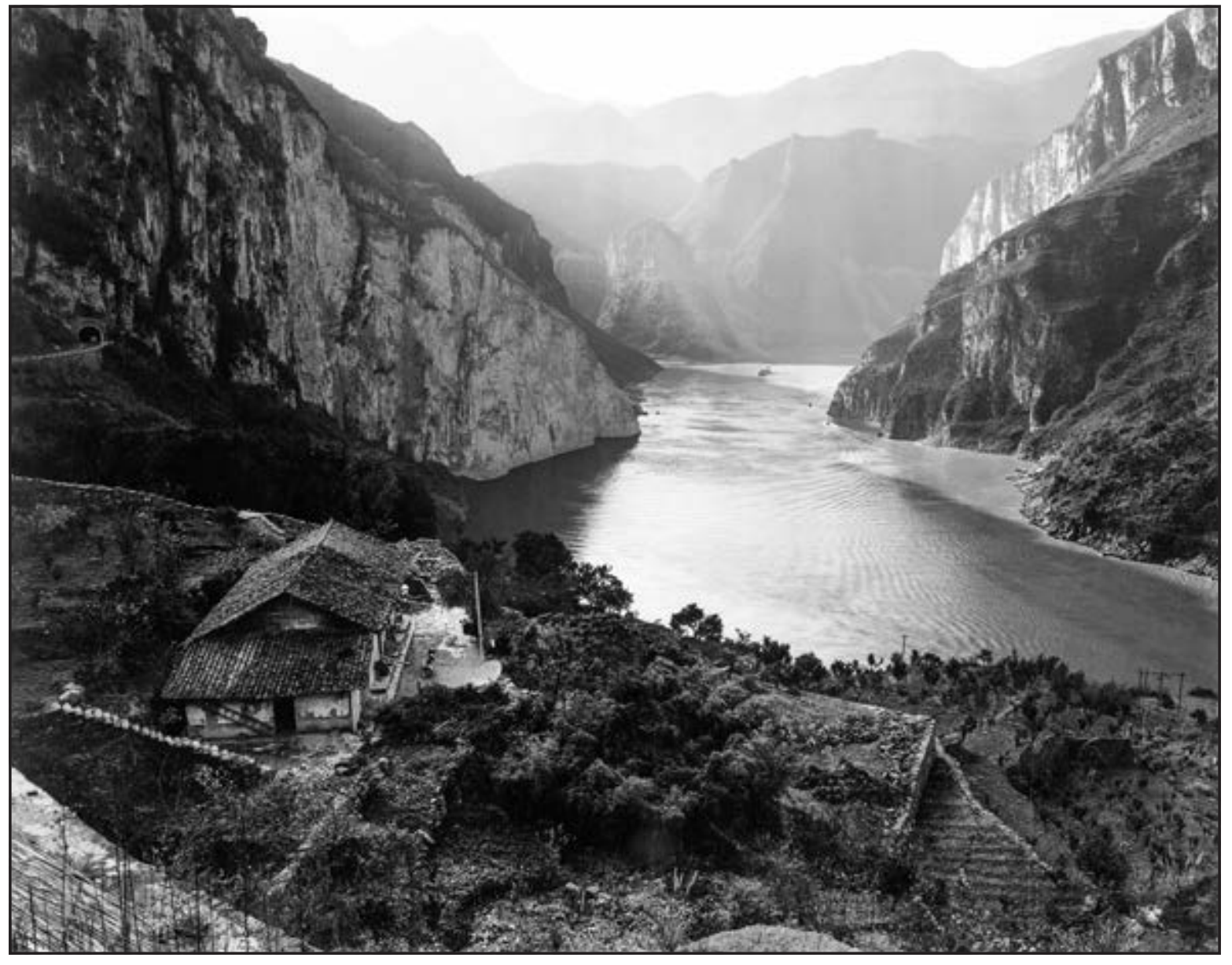

Yangtze Overlook, Xiling Gorge, 2000.

Photograph by Linda Butler.

Xiling Gorge is forty-seven miles long.

The Three Gorges Dam is near its

eastern end. This upstream view

includes a farmhouse with a satellite

dish-a luxury that was rarely seen

in rural areas before 2000-and

a new highway (at left). 